\title{
Local education authority's quality management within a coupled school system: Strategies, actions, and tensions
}

\author{
Jan Håkansson ${ }^{1,2}$ (D) Carl-Henrik Adolfsson ${ }^{1,2}$
}

Accepted: 23 January 2021 / Published online: 22 March 2021

(c) The Author(s) 2021

\begin{abstract}
International policy trends point to an increased focus on student achievement, teaching quality, and school outcomes. Attention to Swedish students' poor academic achievement over the past two decades has resulted in an increased emphasis on the responsibility of municipalities and schools to create a better educational atmosphere through building quality control systems at the local level. The purpose of this study is to contribute in-depth knowledge of not only how local education authorities (LEAs) support and control schools through quality management systems but also how these local governance strategies are conditioned and obtain legitimacy in relation to the national governance of schools. Based on interviews with LEA actors in one large municipality in Sweden, as well as observations of meetings within the quality management system, this paper uses an organizational theory to explore what appears to be important in a LEA quality management system and the tensions between the state, the municipality, and the school. The results show that the LEAs' quality management system is based on three specific strategies: (a) data use, (b) leadership, and (c) different forms of dialogues, which, in turn, contribute to relatively close system connections. The exception is the LEAs' ability to sustainably contribute to equity in outcomes and quality, where different tensions become clear. There is some support for the LEAs' potential to contribute to stability and coherence in relation to national governance and to the local schools.
\end{abstract}

Keywords School governance · Local education authority · Quality management system $\cdot$ School improvement $\cdot$ Coupled school system

Carl-Henrik Adolfsson

carl-henrik.adolfsson@lnu.se

Jan Håkansson

jaha@du.se

1 Dalarna University, Falun, Sweden

2 Linnaeus University, Kalmar, Sweden 


\section{Introduction}

Considering the international policy trends that stress an increased focus on student academic achievement, teaching quality, and school results, governments in many nations have tried to get a better grip on and take increased control over the outcomes of schools and school systems. Therefore, a growing recentralization is another international trend triggering a restructuring and redefining of the relationships between national-, district-, and school-level stakeholders within school systems. Researchers have recently pointed out that the construction and implementation of different forms of quality management systems and quality management strategies at the level of local education authorities (LEA) are increasingly used to control and support quality education and curriculum work at the school level (Wahlström and Sundberg 2017b). However, the relationships between different stakeholders and organizational levels in the (local) school system and the design of and control over quality management systems are vital to school actors, as these play crucial roles for local school improvement and quality management (Campbell and Murillo 2005; Adolfsson and Alvunger 2020). Despite growing research in the Nordic countries about education, knowledge about the relationship between the state, the LEA and the local school is relatively limited. This gap in the literature has motivated studies that deepen the understanding of the LEA's approach to handling the management, monitoring, and support the development of quality education (cf. Paulsen and Høyer 2016; Prøitz et al. 2019). As part of a larger research project, we interviewed the LEA managers with different types of managerial responsibilities at the municipal level and LEA administrators with various strategic and quality-development assignments. In addition, we observed meetings within the quality management system between representatives of the LEA in the current municipality and groups of principals of the local schools. At the LEA in the current municipality (one of the largest in Sweden), there are several so-called LEA managers. Each of them is responsible for a certain geographical area of schools and oversees several principals. The LEA managers' mission is delegated from the superintendent, who, in turn, is responsible to the local politicians in the school board and the municipal council (cf. Paulsen et al. 2014).

\section{Background-The Swedish policy context}

The Swedish school system has been characterized by far-reaching decentralization since the early 1990s, when municipal and independent school boards had the opportunity to exert considerable influence over schools. Attention to Swedish students' poor academic achievement over the past two decades has contributed to an increased emphasis on the responsibility of municipalities and schools to create better educational conditions at the local level. Although there have been recent signs of a recentralization of the Swedish school system through, for example, national school inspections and nationally initiated competence-development efforts, there has simultaneously been an ongoing emphasis on quality management at both the 
intermediate level (LEA/district level) and the school level. What this means with respect to the relations between the state, the LEA, and the schools is a question that this paper focuses on. Even if the relationship between the political leaders and the professional leaders in the municipality is of importance, the focus here is the interplay between the LEA administration in the current municipality through the quality management system and the national as well as the local school governance. Furthermore, the so-called twofold governing of the Swedish school system implies an immediate relationship between the national level and the local school (e.g., through the curriculum and the principal) as well as between the national level and the local policy level and the LEA administration (e.g., through politicians in the municipality, the independent school board, or the superintendent) (cf. Paulsen et al. 2014).

What the overall trends in the governance of the Swedish school system mean at the municipal level has been studied in a Swedish and a Nordic context (e.g., Wahlström and Sundberg 2017b; Prøitz et al. 2019; Paulsen and Høyer 2016; Henriksen 2018; Henriksen and Aas 2020), but the knowledge gaps are still considerable. An evaluation of the latest Swedish curriculum reform for compulsory school (Wahlström and Sundberg 2017b) discusses, among other things, the role of municipalities as independent actors in educational reforms. The results show that in some parts of the implementation of the reform (for example, grades and assessments), the connections between the national and the municipal levels have been strong, whereas in other parts (e.g., the implementation of quality management systems), the control and the connections between the different levels have been characterized as weak or loose. Håkansson (2019) study on preschool principals' leadership shows that larger municipalities tend to align policy and methods for the systematic quality work than smaller municipalities do, without this leading to significant differences in preschools' leadership or in the implementation of quality management. In Sweden, according to the Education Act, it is mandatory for preschools, schools, and local education authorities to conduct quality management, with requirements for results monitoring, analysis, evaluation, and local improvement work. Quality management seems to be an increasingly important way for an LEA to exert influence over the schools and to respond to an increasing recentralization of the school system (Wahlström and Sundberg 2017a; Adolfsson and Alvunger 2020). According to recent Swedish research, parts of the municipal quality management system also seem to have an impact on the long-term development of student achievement (Jarl et al. 2017). A collective concept like quality management includes several components and possible strategies linked to management, evaluation, educational leadership, data use, and peer learning. However, it is an empirical question as to how these components are expressed in the LEA administration's quality management system and within the framework of a decentralized school system but with an increasing recentralization on the part of the state.

Against the backdrop of the tension between national and local school governance, this study aims to examine what strategies and actions, linked to the LEAs' quality management, these educational authorities employ for controlling and supporting the schools. The study intends to contribute in-depth knowledge about local school governance within a decentralized school system. The following research questions have guided the study: 
- What strategies and actions, linked to LEAs' quality management system, do LEAs apply to support and control the schools?

- How do the tension and the interplay between the national and the local school governance condition the LEAs' quality management and with what possible consequences?

\section{Previous research}

Within the research on reform and school improvement, there is a long history of studies on policy-level shortcomings when it comes to their effects on schools, teachers, and classrooms. Researchers have highlighted limitations in both the decentralization and centralization educational strategies. In addition, the same researchers have also pointed out the importance of the intermediate level that in a better way can contribute with systematic methods and coherence at the local level, rather than isolated successes or failures due to the activities of an individual school (cf. Campbell and Murillo 2005; Hopkins and Woulfin 2015; see also Fullan 2005). Previous research has shown that different levels or layers in the school system need to interact and move in the same direction, not least to create sustainable, in-depth changes (Håkansson and Sundberg 2016). Fullan (2009) highlights the concept of "tri-level reform" to illustrate the need to locally support different system changes and create opportunities for the different levels to interact regarding improvement initiatives. If school leaders and teachers are only seen as the implementers of new instructions or methods, the risk that reform attempts will remain on paper is obvious (cf., e.g., Cuban 2013). Felner et al. (2001, 2008) propose an ecological model as a theoretical basis for implementing improvement strategies in the school. Such a model emphasizes the interplay between different 'ecosystems' - such as the LEA administration, school leaders, teachers, parents, and pupils-for developing not only the pupils' knowledge outcomes but also the schools' and pupils' entire development and learning progression. The question in this study is how one of the components of an ecosystem or a 'coupled system,' namely the LEA administration in one municipality, perceives and handles its role and function in the middle (as an intermediate level) of management and which strategies and actions in the local quality system are emphasized in relation to the schools within the municipality's area. What tensions arise, and how does one meet them? Although the LEA administration has sometimes been overlooked in mainstream reform and school improvement research, several initiatives have been taken by research teams to fill the knowledge gaps as to the role and significance of this mid-level of the school system. For example, in a comprehensive research overview, Rorrer et al. (2008) state, "Clearly, given the research synthesis presented above, districts do matter" (p. 332). As an institutional actor when it comes to supporting the improvement of academic performance and increasing equity, the role of the LEA administration or the district can, for example, be linked to "their collective identity and their ability to create change by altering institutional scripts that tacitly and explicitly govern the behavior of organizational actors" (p. 332). The strategies that the LEA administration chooses, thus, appear to 
be able to make a difference, both on a conscious level and more imperceptibly and implicitly.

Internationally, so-called LEA (Great Britain) and local central authorities (LCAs, district level in the United States) have an influence on policy implementation, and students' academic outcomes are investigated with varying results. The impact of change initiatives from a higher level depends to a large extent on how active the LEA's role has been and the extent to which selected strategies have emphasized accountability regarding student outcomes or, for example, the creation of networks between schools in the municipality or district (cf., e.g., Fullan 2005; Lee et al. 2012; Louis 2013; Campbell and Murillo 2005). While it is difficult to comment on direct links between the level of LEA administration and, for example, students' academic performance, the research has identified successful strategies that can support local school improvement in the given municipality or district (cf. Leithwood et al. 2019). Campbell and Murillo (2005) highlight the opportunities that LEAs have to support school improvement through, among other things, improving political and professional leadership, strategic education planning, focusing on and leading school improvement, committing to improving school outcomes, and achieving a stable and secure infrastructure for education (including the localization of schools and resources) (Campbell and Murillo 2005, p. 81; see also Leithwood et al. 2019).

Rorrer, Skrla, and Scheurich (2008), who conducted a research review based on about eighty research studies, identify four roles that the LEA/district can take up to promote improved academic performance and increased equity: (a) providing instructional leadership, (b) reorienting the organization, (c) establishing policy coherence, and (d) maintaining a focus on equity. According to the researchers, these four roles are interdependent and interconnected in different ways (loosely or closely) in a nonlinear process. The way the roles are interconnected is important for how the district can function as an institutional player in the context of academic improvement and increased equity. In this research review, the concept instructional leadership is given two meanings. First, it is about local will to change, which is here linked to attitudes, motivation, and personal responsibility in relation to improvement goals and strategies. The active and enthusiastic role of the school principal, through proactive administrative behavior, is stressed as creating commitment to improvement, among other things, by establishing a vision and a targeted focus. Second, instructional leadership builds local capacity in the form of knowledge and skills, which generate actions that, in turn, help to mobilize staff, to develop functions linked to change, and to create links between the district level and the school level. Understanding and getting others to understand the idea of reform depends on various kinds of resources that can help improve communication, planning, collaboration, monitoring of goals, instructions, background data, transparency, and accountability. The second role, reorienting the organization, stands for, on the one hand, refining and adapting structures and processes by consciously adapting actions to the improvement goals through decentralization to strengthen participation and contribute to better communication in the system. On the other hand, the term relates to cultural change (norms, expectations, and values), in which the school leader's 
responsibility for creating a culture of commitment and effort, is emphasized. The third role, establishing policy coherence, consists of two parts: a strategic adaptation and modification of external requirements, strategies, and goals to local needs as well as an adaptation of financial and human resources to local needs. Rorrer et al. (2008) stress the importance of not underestimating the role of the LEA administration in acquiring, adapting, and distributing human resources (both administrative support and teacher competence) in line with the overall and external goals. Within the framework of the fourth and final role, maintaining a focus on equity, attention is directed to the school administration's moral responsibility for finding solutions that address injustices, by including the issue of equality in, for example, development plans, policies, strategies, and decision making (Rorrer et al. 2008).

In the present study, the type of analytical framework that Rorrer et al. (2008) present is important for identifying the focus and the strategies emphasized by the municipal-level officials responsible for, among other things, improvement in academic performance and increased equality. Needless to say, there are many differences between different countries' control systems and the role, responsibility and functions that LEA possess. At the same time, there is a need to study organizations in similar intermediate positions in more detail because they generally happen to be under constant pressure by a number of-sometimes incompatible-requirements from different stakeholders in the system (cf. Seller 2005).

Research linked to a Nordic context shows that superintendents are regarded as important players in the municipalities' quality systems and that supportive forms of leadership by superintendents can contribute to school leaders' ability to handle conflicting demands and expectations. Yet there is also a need to know more about the learning environments where the LEA and principals interact (Moos et al. 2016a, b; Paulsen and Henriksen 2017). Prøitz, Mausethagen, and Skedsmo (2019), for example, identify different characteristics in LEA administrators' manners of controlling data use in Norwegian schools-one controlling and one developing. The researchers assert that a decentralized school system allows for differences in the municipal level's way of handling, for example, data from national tests in relation to the school leaders. Scope in the local policy allows LEA administrators to emphasize, on the one hand, a narrow understanding of learning outcomes with reporting, documentation, and measurement of effects and, on the other hand, a broad understanding of learning outcomes emphasizing discussion and collective ownership of results as well as the measurement of results through dialogue (ibid, p. 17). The Norwegian study contributes valuable knowledge to the study presented in this paper. Similarly, comparative research in the Nordic countries shed light on important issues, such as superintendents' position in center of tensions between external evaluation and the facilitation of professional learning (cf. Paulsen et al. 2014). However, while the Nordic countries show similarities in governance and organization to an extent, they are also part of a global accountability trend with strong demands for improving results and introducing different quality management systems (cf. Datnow et al. 2019). This reality contributes to the possibilities in the present study to draw lessons from and build on research from both neighboring countries and other parts of the world. 


\section{Theoretical points of departure}

The state, local school authorities, and individual schools are central institutions within what we used to call "the school system." Based on the study's research questions, it becomes important, on a theoretical level, to understand the character of the relations between these institutions but also the character of the internal couplings within an institution.

A way to analytically understand the character of these relations in terms of, for example, hierarchical levels, different functions or groups, and external conditions, is through the concept of couplings (Orton and Weick 1990; Weick 1976). Coupling is crucial in the way it contains aspects of both distance and proximity within an organization and aspects of openness and closeness in its external relationships to other organizations. Orton and Weick (1990) argue that what constitute a specific organization is the character of the links between the organizations' internal subsystems and how the organization interacts with the surrounding context. Several studies have shown that the character of the external and internal couplings between and within an organization has consequences for school reform implementation, the management and the assessment of the school, school leadership as well as the outcome of local school improvement initiatives (Spillane et al. 2011; Adolfsson and Alvunger 2017). Taking the couplings as an analytical focus, a distinction can be made between tightly coupled, decoupled, and loosely coupled systems (Orton and Weick 1990; Weick 1976).

An organization where the couplings between the internal subsystems are strong and have a high degree of responsiveness for external influences can be described in terms of a tightly coupled organization. In contrast, in a decoupled organization, the internal couplings are distinct, which means that there are clear boundaries between the internal subsystems. The subsystems, thus, possess a high degree of autonomy in relation to each other. However, the same degree of autonomy exists in relation to external organizations, which implies that a decoupled organization has a low responsiveness to external influences and pressure. Finally, in loosely coupled organizations, the external couplings are responsive, while the internal couplings are distinctive. Such a system is open to external pressure and change, but at the same time, it has boundaries between the internal subsystems (Orton and Weick 1990; Weick 1976).

Several studies have described the school system in terms of being loosely coupled and sometimes even decoupled, which in turn has consequences for educational reform implementation and the management of the school (see above). This situation can, in some cases, also explain why educational reforms or school improvement efforts do not happen in the intended way. However, the degree of the strength in the couplings within and between organizations is primarily an empirical question. For example, Rorrer et al. (2008), who examined the role of school administrations as institutional actors in school improvement, state that the couplings between the subsystems are characterized precisely by variability. That is, the couplings can be both tight and loose, even in one school system. It may even be that tight couplings in one part of the system can only occur if there are loose couplings in another part of the system (Rorrer et al. 2008, p. 337). The patterns of couplings between the various 
parts of the system that can be identified in this study are important for understanding the LEAs' handling of various aspects of the quality management system in relation to the state and the local schools.

Considering the aim of this paper, and linked to the discussion above, it raises questions about how different institutions, for example the LEAs or the state, try to influence and control an organization, for example a school, and about what elements are included in such control. Based on such questions, the neo-institutional theory (Scott 2008) can provide theoretical clarity, since it is concerned with questions of institutional change and processes of conformance and legitimation within and between social organizations (such as schools) in relation to surrounding institutions (Scott 2008).

Scott (2008) emphasizes that traditional regulatory aspects, such as laws and mandatory directives, only constitute one aspect of how institutions seek to control other social organizations in a legitimate way. In addition, besides the regulative elements of control and legitimacy, Scott (2008) points to the normative and the cultural cognitive aspects.

The regulative aspect emphasizes rule setting, laws, monitoring, inspections, and sanctioning activities. This kind of regulative elements gives institutions legal legitimacy. Through this institutional elements, different mechanisms of regulating control and change become crucial. Such mechanisms are characterized as mandatory and, therefore, often emanate from formal and authoritative offices and agencies. Linked to the Swedish educational policy context, this could, for example, comprise the national Education Act, the national curriculum with its prescribed knowledge standards as well as the Swedish Schools Inspectorate.

The normative element of an institution comprises the values and norms that provide the basis for obligations, prescriptions, evaluations, goals, and means (Scott 2008). That is, different forms of acknowledged social agreements of expectations and conventions that anticipate its members to act in a specific way. Such pressure may arise from norms, expectations, and attitudes linked to how schools should work and take appropriate action. In the absence of legal obligations, the normative element primarily operates through soft regulations with no formal legal sanctions attached. Consequently, the normative aspect of the institution comprises another way of exerting control, changing processes, and obtaining legitimacy.

Finally, the cultural-cognitive element can also be defined as a more softly regulated element of control. However, compared to the regulative and the normative aspects, this element is primarily linked to an actor's shared cognitive and discursive conceptions and frameworks, providing an avenue toward different meanings. That is, within and between institutions and social organizations, common sense or what is taken for granted is formed around what can be regarded as correct and legitimate beliefs, opinions and modes of behavior (Scott 2008). That is, this common sense will constrain and enable a certain thinking, decision making and action linked to, for example, teaching, school improvement, pupils with special needs, and so on.

Linked to the aim of this study, the normative and the cultural-cognitive elements of control and legitimacy can therefore contribute to an understanding of how a deregulated and decentralized system, such as the local school system, can be controlled and become stable over time (Nordholm 2016). 
In sum, the theoretical framework that has been sketched above, inspired by organizational and neo-institutional theory, will contribute several analytical concepts important to analyze, as well as to better understand, the character of the strategies and actions linked to LEA's quality management system.

\section{Method and analytical framework}

The overall methodological approach is qualitative, as it is based on the school actors' understanding of the practices of which they are a part. But the study is also explorative in nature, given that the knowledge gaps in the area appear relatively large (cf. Cohen et al. 2011; Patton 2015). We see opportunities within the scope of the study to contribute to analytical generalizations through theoretical interpretations of the data that emerge as well as opportunities to generate new questions for further investigations (cf. Kvale and Brinkmann 2014). This study expands and deepens an ongoing three-year research collaboration between a larger municipality in Sweden and a university. The purpose of the larger research project is to follow and analyze different parts of the municipality's quality management system and the consequences that appear in a sample of primary and secondary schools regarding building capacity for school improvement. In the present study, however, the focus is primarily on the LEA administration's position as an intermediate level in the school system as well as the strategies used and the tensions that become apparent in relation to both the local schools and the state. There are, however, limitations to this study, such as the focus on only one municipality. Yet the municipality's size and the number of staff in the LEA administration have meant access to rich and varied data.

The data collection was carried out via a multi-method approach (cf. Tashakkori and Teddlie 2010); individual interviews with various LEA actors were combined with observations of meetings between LEA administration representatives and school principals. The target group for the interviews was the LEA administration staff, including both decision-making personnel (for example, LEA managers) and people with operational tasks in the quality system (for example, investigators, development strategists, and coordinators).

In total, 13 individual and semi-structured interviews were conducted with seven LEA managers with different types of managerial responsibilities at the municipal level and six administrators with different strategic and quality development assignments. Each interview of approximately $60 \mathrm{~min}$ was recorded, listened to, and transcribed. In total, the written interview material comprised about 80 pages. The semi-structured interviews were guided by an interview guide thematically arranged based on three main areas: (a) the LEA's strategies in relation to school improvement; (b) specific parts of the LEA quality management system, such as data use and analysis; and (c) the state-municipality-school relationship regarding quality management. In addition, observations were made of dialogue meetings within the quality management system between representatives of the LEA administration and groups of principals of the local schools. The observations were semi-structured in the same way as the interviews. That is, field notes of the dialogue during the meetings were taken based 
on a number of concepts with the aim to reflect the municipality-school relationship regarding the quality management system-for example, clarity, responsibility, and legitimacy in relation to parts of the quality management system as well as hindering and facilitating circumstances in the implementation of the quality management system (cf. Sannerstedt 2001). The field notes, including the researchers' reflections on the observations made, comprised about 30 pages of verbal transcripts. All participants received information about the purpose of the study and agreed to participate in observations and interviews. Respondents were informed about the way the data would be handled and how the results would be used and presented (cf. Vetenskapsrådet [The Swedish Research Council] 2017).

The analyses were carried out in several steps. In the first stage, repeated reading of the transcribed material in relation to the first research question was carried out - a type of deductive and contents-wise sorting and reduction process in which significant statements related to the quality system and the LEA's strategies within its own quality management system were manually coded to create preliminary patterns in the material based on the informants' different emphases (cf. Rennstam and Wästerfors 2011; Bryman 2002). The second step was based on a more open and explorative approach. The second question, about the quality management system's challenges and tensions, was used to identify examples of ambiguities, problems that may arise, or uncertainties based on the intermediate position LEA in which actors find themselves. In the second stage, attention was drawn to variations in the respondents' statements to analyze the way in which different positions within the LEA generated different perceptions about the quality system, selected strategies, and tensions. The overall analysis in the third step focused on the connections between the different parts of the quality management system in terms of the strategies the LEA uses and in relation to Rorrer et al.'s (2008) theoretical framework of how the LEA's roles interact more or less in the pursuit of improved academic performance and increased equity (cf. also Orton and Weick 1990; Spillane et al. 2011). In addition, the neo-institutional theoretical and conceptual inspired framework (Scott 2008) described above enables us to distinguish and elucidate the characteristics of these strategies, which the LEA initiates with the aim to influence and control the schools, as well as how these strategies obtain legitimacy in relation to national regulative aspects.

\section{Results}

In the following section, the empirical results are presented based on the study's two research questions. The first part, thus, focuses on the LEA's strategies and actions for following up, supporting, and directing the schools' work toward increased goal fulfillment, equity, and development of local improvement capacity. What challenges and tensions can be identified from an LEA perspective and in relation to the quality management of local schools and national governance of the schools? 


\section{Overall strategies in the LEA quality management system}

According to the Swedish Education Act, all local school boards, schools, and preschools must conduct quality management by "systematically and continuously planning, following up and developing the education" (Sweden 2010; Education Act, chapter 4, Sect. 3). At the school level, principals are responsible for the local school improvement, with the participation of teachers and pupils. A collective concept such as quality management contains several method and content components, such as results monitoring, evaluation of different curriculum goals, analysis and various forms of documentation, as well as many aspects that can be linked to processes of local improvement work at different levels. The content of the current school improvement can have to do with, for example, work on goals and visions; direction, leadership, and organization of school and classroom processes; and leadership and change work in the local school culture. In the municipality studied, the quality management emerges as a unifying strategy, with two main parts. According to the interviews conducted, the overall parts consist of two main focuses, which fulfill the political and overall objectives for the municipality's compulsory schools: partly improving students' academic performance ("increased goal achievement") and partly increasing equity between schools. This focus has been preceded by a trend of declining academic performance in the municipality in question as well as increasing differences in results between schools in light of, among other things, population segregation linked to different neighborhoods. Recently, the LEA has also implemented a new geographical-area breakdown for the schools, with the aim that schools (and principals) with different socioeconomic conditions will belong to the same group of schools and meet and work together to contribute to increased equity.

The interviews show that an overall strategy in recent years has been to develop a strategic framework for quality management based on a professional development initiative for all school leaders, including the LEA and school politicians in the current municipality. The training has been conducted within the framework of international school leadership (ISL), based in Ontario, Canada, with training modules for both school system leaders and school leaders. Relating to the educational effort in the Swedish municipality and with ISL as a model, a local strategic framework consisting of the following four components has been developed: (1) common direction, (2) leadership, (3) learning, and (4) quality and improvement work based on data and evidence. According to one of the LEA managers, it is about what "... we want to do in our schools to make a difference for the students, and we have been very inspired by Ontario and the ISL training that all school leaders go through" (LEA manager 5). At the same time, the municipality's involvement in the ISL training raises questions: "The administration ordered a leadership training, ISL, which all the principals were to attend. And it has been good, but I wondered on what basis they came up with this" (LEA administrator 5). Although these overall objectives and frameworks are highlighted in the interviews, there are three more specific strategies and associated routines for meetings and documentation that are emphasized and that are the focus of the LEA's 
quality management system for the schools within the municipality: (a) data use, (b) leadership, and (c) different forms of dialogues.

\section{Data use}

Based on the empirical material, data use appears to be a very important strategy in quality management. It is based, in turn, on a comprehensive following up of results and is presented as the key to conscious, neutral, and research-based improvement work and to get away from personal opinion and temporary, poorly supported solutions in the school improvement work. As one LEA manager put it, "After all, data is the neutral part. It is not about you as principal but about the results of the school. For we have this data, of course. And it's hard to argue for anything else" (LEA manager 2).

At the same time, there is a strong focus on controlling the school's data usage: "Now we are more aware that we [LEAs] are increasingly choosing which data to analyze" (LEA administrator 2). But they are also helping the schools develop tools to analyze results and development work based on data. LEA administrators with strategic or development assignments also note the difficulties involved in bringing about conscious data use and evidence-informed decisions at the overall municipal level:

For a long time, we have found that we are unhappy with the results in mathematics at several of our schools, and we have had some measures connected to that, but it rests there ... we just haven't found a system for finding the causal relations to be able to decide on the right actions ... we don't really have anyone who has the overall picture here and who can have the helicopter perspective. (LEA administrator 3).

LEA managers focus more on the schools' and especially the principals' successes and difficulties with the use of data in their quality management. In the interviews, they highlight how data influence a variety of different activities and conversations they carry out with the principals as well as how they try to inspire principals to use data together with their teachers. The use of various supporting materials, according to LEA managers, leads to changes in the principals' attitudes to data and in their competence: "Now I see a demand for more data and how we use it in depth and breadth, and it leads us further in looking at data next to each other. We no longer look at one piece of data at a time" (LEA manager 1). Data-based quality management is simultaneously perceived to consist of a relatively difficult-to-penetrate mass, a bunch of different types of data, both quantitative and qualitative: "We have endless amounts of data, but do we see what we want to see or do we see what is easy to see?" (LEA manager 3). The schools may also find it difficult to orient themselves in the amount of different data: "Schools collect such an awful lot of data and background information of all kinds. Then they don't know what to do with it ... so you get a little more material so it can help answer everything else, until finally you drown in it" (LEA administrator 3). 


\section{Leadership}

The other very clear strategy in the quality management system is the LEA's focus on leadership, especially as exercised by the principals in the local schools. There are several different contexts and constellations where principals are expected not only to receive messages from the administrative level but also to interact and learn together with other principals in, for example, leadership forums, principals' meetings, workshops, and seminars. LEA managers also describe a cultural change in their own group of LEA managers in recent years, which has to do with modeling the principals' work to a greater extent through their working, as LEA managers, in a way that they expect the principals to work: "As LEA manager, I work with my class, and the principals must have the tools to work with their closest class, the teachers, student health, and more" (LEA manager 2). The LEA managers also collaborate in their management team to create a common direction in the various principal groups they lead: "We also lead with the same purpose in the different constellations, and this has provided a tremendous amount of power so that when we go out and meet our principals we have the same purpose with where we are going" (LEA manager 1). The role of the LEA manager also includes developing the principals' leadership by "challenging and not just patting them on the back" (LEA manager 3). This means, according to the LEA managers, that the role is about showing, through the LEA managers own challenging leadership, how to develop the leadership of other principals.

\section{Dialogue}

The foundation of the third strategy, dialogue, consists of so-called quality dialogues, in which LEA managers and principals meet in structured discussions about school results, improvement work, and aspects that are included in the strategic framework. The quality dialogues take place four times a year with a specific agenda aimed at not only strengthening the analysis and improvement work at the school but also contributing supporting material to the LEA's quality management work. More recently, the target group in one of the quality dialogues has been expanded to include the schools' development groups (or the equivalent), which also include assistant principals and teachers with development assignments. The dialogue strategy also includes LEA managers' so-called business visits and individual conversations. During the business visits, classroom visits are sometimes conducted together with the school's principal to get acquainted with the everyday work and with the extent to which the ongoing development work has reached the teachers and the teaching. According to LEA managers, it is important that the various dialogues, business visits, and conversations are not perceived as an external control, but they point out at the same time that they need to gain insight into the different schools: "We want to keep tabs, and there is a difference between keeping tabs and control" (LEA manager 1). 


\section{The LEA and the quality management system in relation to the local schools}

As a way of combining the two strategies of data use and dialogue, there are also different types of in-depth or learning dialogues in the municipality about different data on academic performance, teaching, and other influencing factors. These meetings take place in parallel with the so-called quality dialogues that LEA managers conduct. The idea is that the LEA administrators with development assignments should support the schools' work during regular school visits by documenting the results and other data, and precisely this support has been implemented in different ways in recent years. One observation from the interviews with LEA managers and LEA administrators is that these meetings are perceived by several school leaders as parallel and very similar tracks - one linked to formal leadership and another linked to the LEA's support functions. On the one hand, there is a point to management and support being handled by different functions in the organization; for example, it may be easier as a principal to ask for help and support to a person in the organization that is not the principal's formal boss. According to one of the LEA managers, schools may also need "different support than they can get from me" (LEA manager 4). On the other hand, if very similar processes and dialogues are handled similarly by different LEA actors (LEA managers and LEA administrators), there is the risk of a perception that LEA as a whole steals time from the schools.

Field notes from observations of so-called quality seminars with groups of principals indicate an intention to begin with the participants' experiences and to think together about ongoing processes of data collection, analysis, and development work at the schools. At the same time, it becomes clear that the principals perceive the LEA's various activities vis-à-vis the schools in different ways. Some of the principals use the term "shoehorn" to illustrate how, as a principal, they sometimes need to integrate the LEA's management and support strategies into what is going on at the school. The discussions also show that there is uncertainty about the management personnel's expectations of the school leaders and the key people the principals have appointed to participate in the LEA's various school visits. This seems, among other things, to be related to a lack of understanding among the personnel about what quality management entails at the school and municipal levels. The overall impression from the quality seminars, however, is that there is a legitimacy to the various features of the LEA's quality management system that the schools and principals are getting in contact with. However, at the same time, there is no lack of critical views and exchange of arguments and counterarguments between LEA managers, LEA administrators with development assignments, and principals.

The municipality's quality management system also includes a structured model for how the quality work should be documented at the school level, a quality report summarizing results, analyses and conclusions, and a commitment plan for planning upcoming development work. These documents, thus, form an important basis for the various dialogues and conversations that are conducted within the quality management system. According to the interviews, the standardization of the schools' documentation over time has contributed to the municipality's being able to identify strengths and development areas for the entire municipality's school operations in a more systematic way. At the same time, the standardized document structures 
and the other general parts of the quality system do not appear to be entirely effective: "We have structures to support everyone, and for some schools it works well, but some schools don't budge" (LEA administrator 5). The uniformity of structures, dialogues, and support does not seem to have a sufficient impact on what the LEA wants to influence- - to equalize the differences between schools and to increase goal achievement and equity:

It's the same strategies. No unique efforts are being made here for individual schools, and unfortunately, it is the case that, if a school is failing, then an emergency intervention is needed. But the administration has no real ownership for entering at an earlier stage before we end up in that emergency situation (LEA administrator 1).

When the general strategies for management, control, and support do not workthat is, when some schools do not achieve expected results regarding the students' academic achievement - the LEA seems to primarily use strategies involving the principals of the schools. These strategies may involve working with more frequent reviews with the principals or, together with the principal, deepening the analyses to find out what the actual needs are in, for example, the teaching. In some cases, the LEA managers look for a more thorough systematic approach from their side: "Just in this case, we and I should have been more systematic in sending help. I backed off; I just sent people there. But more is not always better. Sometimes it is better to stay calm. A deeper analysis should have been done. We didn't catch them on time" (LEA manager 3).

The means the LEA uses to reverse the development in schools with weak performance in these and similar situations can be described as essentially negotiating and building on dialogue but also, in some cases, as corrective, that is, sometimes you need to "... run over people to bring about change" (LEA manager 5). According to the decentralized Swedish school system, principals have relatively large decision-making autonomy regarding the school's internal work. The interviewees also emphasize, in line with this, that the LEA should not "take over" school leadership and that the principals' responsibility for results also includes the LEA's responsibility to create the conditions for all students to get through school with passing results. Instead of correcting schools and principals in retrospect, the ambition of the LEA is to work preventively, with the recruitment of principals, for example: "[It is] important to think about which principals we should recruit. After all, you can't come in as a principal and believe that you can just go your own way" (LEA administrator, 2). Principals recruited from municipalities other than their own are said to be in a poor starting position in terms of knowledge: "The principals who come from outside have more to learn than those we have brought up ourselves and who are within our culture" (LEA manager 2).

Although many "disruptions" in different parts of the quality management system can be identified, the interviews highlight the main merits of the overall quality management and indicate that it will, at least in the long run, affect the results and quality in the schools. However, there are some differences of opinion between different LEA actors regarding the qualities of the quality management. LEA administrators with strategic and development assignments are more likely to see the shortcomings 
in the quality management system, especially regarding the municipality's ability to compensate for differences in results and other qualities in the schools. LEA managers emphasize how they, as leaders, can bridge the gaps and compensate for things that the quality system itself cannot access.

\section{The LEA and the quality system in relation to the national governance of schools}

Based on the interview material and the actors found in the municipal school administration, an image emerges of the state as a legitimate actor in the control system regarding quality management. The understanding is that the statutes relatively clearly define the division of responsibilities between the different levels of the school system, while extensive work needs to be done at the local level to transform the state's intentions into a quality management system that contributes to the local development work: "We have worked for several years to bring the municipal together with the national governance" (LEA administrator 1). Thus, it is not obvious how the state's intentions should be translated into local quality management, nor are the boundaries between the municipalities' and the schools' responsibilities given: "What do these intentions really say about what we, as responsible officers, should do and how we can do it without stepping over the boundary of what schools have the right to decide for themselves?" (LEA Administrator 2). There are also perceptions that the local interpretation of national requirements and intentions involves an unnecessary detour when, in the end, the national goals are achieved: "The municipality wants to make its own mark. But I think it's a difficult job. It is easy to distort and change ... but then you still have to go back and start from the national goals" (LEA administrator 3). The interviewees' descriptions show the autonomy that prevails regarding the quality management as well as how the state's guidance can be used to qualify the construction of their own quality management system. In the same way, there is still a need for a holistic view of the nation's school system and performance development so that different special interests or local solutions do not create too great of differences between the country's different municipalities and schools.

The overall picture of the state's role in relation to the municipality's quality management system contains, however, several nuances that challenge the coherence of the control system. The clearest expression of this is the view that different types of general and targeted state grants contribute to disruptions in the municipality's efforts to build up the capacity of schools through local improvement work and, thereby, improve students' study results. From the political leadership of the municipality in question, it has been stated that all government grants that are advertised must also be applied for and requested, which has meant a lack of a long-term perspective in the development work. According to the interviewees, this situation can contribute to a culture of ensuring that money is spent rather than being based on the needs of the schools in the municipality: "When I look at it from an educational perspective, I can't see that this is well spent money" (LEA administrator 3). Even within the national school development initiative concerning teachers' professional development in teaching mathematics, there is partial financing from the state that 
the municipality has been able to apply for, which has also not been problem free: "Sometimes it's amazingly bad ... I think this mathematics professional development is such an example. If the schools that have a need for it do it, then it can be good. But it easily happens that when resources come from the state, one jumps on it" (LEA manager 4).

From the municipality's perspective, it can be difficult to "see the forest for the trees" in the national strategies for improving school results. That is, the multitude of different major and minor investments, in addition to the general governance that is found in the school law and curricula, cause the local school administration to face a dilemma. Based on what is said in the interviews, this can partly be explained by the political dimensions of the governance: "You need to talk to citizens about something. But talking to citizens is not the same as managing an activity or operation. They are two completely different things" (LEA administrator 4).

When it comes to the municipality's relationship with the national governing body regarding performance development, one investment is highlighted as important: cooperation for the best school (CBS). In CBS, one of the national school authorities, the National Agency for Education, collaborates with several universities in the country to support schools with poor knowledge outcomes and with difficulties building their own capacity for development. In the municipality in question, four compulsory schools have been selected based on the Swedish Schools Inspectorates' assessments, and the municipality has agreed to participate for a three-year period. Considering what emerges in the interviews, this is a type of government control that can strengthen the municipality's ability to construct an independent and functioning quality system. The content and organizational structures that are built up at the schools involved with the CBS with the aim of linking the school's various levels and subsystems seem to coincide with the intentions of the municipal quality management system for the school. As one LEA administer said, "I see what has been going on at our CBS schools as incredibly positive, and we have been quite careful that the municipality's quality model and CBS should be linked together, and we have even spent some time talking about principals concerning this" (LEA administrator 3).

Although CBS has so far provided valuable lessons at both the school and the administrative levels, especially regarding the analysis phase of the quality management, there are some concerns about what such "double control" could mean. The LEA managers perceive the Swedish National Agency for Education's interventions in schools as problematic to some extent, considering the decentralization intentions in the Swedish school system: "We are, of course, a big responsible entity, so of course we have resources, so maybe we should not have anyone from the outside, in the project. Rather, we should create our own routines and habits" (LEA manager 3 ). But the advantages of CBS still seem to outweigh the disadvantages, according to the LEA administration's actors. And the explanations for why the national school improvement initiative has been so well received by the municipality can also be linked to an aspiration to be compliant with the state level: "We really want to keep up when the state does something ... it's a signal that we want to cooperate" (LEA manager 5). The interviews show that the state's intentions and ambitions about improving results and increasing equity affect the municipality's quality 
management system more or less while they also more or less coincide with the municipality's own intentions and ambitions.

In the next part of the article, the discussion, the intention is to go back to the study's questions and discuss what lessons can be drawn from previous research and the chosen theoretical perspectives.

\section{Discussion}

Against the backdrop of a recentralization trend within the scope of the Swedish decentralized school system, new governing conditions have merged between the state, the LEA, and the local schools. In light of this policy movement, the purpose of this study has been not only to contribute in-depth knowledge about what strategies and actions the LEA can apply to support and control—-through their quality management system-the schools, but also to show how this quality management is conditioned by the tension between the national and the local governance of the school.

\section{LEA's quality system—Standardized strategies and supporting elements}

The results show that the municipality's quality system is based on a few overall objectives, including a strategic pedagogical framework to develop system and school leadership. The operative work is based on three more specific strategies with associated structures that are emphasized and that comprise the center of gravity in the LEA's quality management of the schools within the municipality: (a) data use, (b) leadership, and (c) different forms of dialogues.

Through the Swedish Education Act (SFS 2010:800), the national curriculum, as well as the Swedish Schools Inspectorate, much of the regulative power within the Swedish school system is situated on the national level. Accordingly, the LEA's strategies and actions are characterized by more normative and cultural-cognitive elements. Notably, the Swedish Education Act emphasizes that the LEA and the superintendent has an operational responsibility for leading principals and for resource distribution and is held accountable for ensuring that education is aligned with the national objectives as well as legal requirements and ordinances involving the schools. Consequently, the LEA's strategies of control can obtain legitimacy by referring to regulative elements in this case the Education Act. (cf. Adolfsson and Alvunger 2020).

The normative elements of the LEA's control of the schools are characterized by standardization and routinization of the LEA's quality management processes linked to the schools' improvement processes and results. These normative elements not only become visible in the form of clear consistency in document structures, reporting, and requirements of how schools' analyses are to be carried out but also in the organizational structures that handle dialogues within and between schools, between schools and LEA, etc. The cultural-cognitive elements, in turn, can be linked to the LEA's strong focus on leadership and to the different forms of individual and 
organizational learning through the actors' communication about and interaction with data and evidence within and between different levels of the system. Within this current local school system, common sense related to what is defined as a good leadership as well as a high-quality school improvement work has been established. An example of such a common-sense approach comprises the ideas of data-based decision making. That is, all decisions linked to the schools' improvement strategies must be based on a systematic analysis of valid data. The strategies that emphasize data use and evidence are also used extensively to legitimize the entire quality system (cf. Datnow et al. 2019). In line with earlier Nordic research on municipal quality management and superintendent leadership, this study shows a blend of standardized and supporting strategies. The latter can enable fruitful relations between different levels in the municipal school hierarchy (e.g., by way of dialogue meetings between superintendents/LEA managers and principals) (cf. Henriksen 2018).

\section{Consequences of the municipality's quality system-tight and loose couplings}

One way to understand the potential consequences of the municipality's quality management system is to relate it to previous research that has identified four mutually dependent and, to varying degrees, interconnected roles that the LEA can take up to promote students' results and increased equity: (a) providing instructional leadership, (b) reorienting the organization, (c) establishing policy coherence, and (d) maintaining a focus on equity (Rorrer et al. 2008). For the purposes of this study, we note that the quality management system of the municipality in question is characterized by mainly tight couplings with three of the above-mentioned roles, namely (a) providing instructional leadership, (b) reorienting the organization, and (c) establishing policy coherence. Strategies that emphasize instructional leadership create the conditions for building a local will to change, with motivation and responsibility in relation to improvement goals and strategies in parallel with a strong focus on local capacity in the form of knowledge and skills to bring about effective communication, planning, and collaboration concerning different types of data. In this, the LEA managers' active leadership and the ever-present question to the principals concerning how they can use data to determine the school's current state and development needs seem to play a significant role. The interaction and connections between reorienting the organization and instructional leadership are most evident in the LEA's quest to decentralize and to strengthen local participation and commitment. To some extent, however, attempts at local adaptation are counteracted by an ongoing standardization of structures and processes in quality management, although this could also, in the long run, accommodate variations depending on the schools' different conditions. The third component or role, establishing policy coherence, also has a relatively close connection to the first two, mainly through the adjustments and modifications made by national regulations and goals in combination with general lessons learned from school improvement and school leadership research. Allocation of administrative support and teacher competence is ongoing, but it is not differentiated or fully adapted to differences between schools, which indicates somewhat weaker connections in the quality management system (cf. Rorrer et al. 2008). 
When it comes to the fourth role, maintaining a focus on equity, the connections are much looser than the other three. Although the quality management system strategies largely aim to strengthen equity in the system and to even out the differences in results and quality between schools, it is at this point that different types of obstacles and tensions become clearest. LEA actors mainly express two things: first, the LEA's quality management system has so far not been able to strengthen the leadership of the schools in a way that affects teaching and pupils' learning and academic achievement at the schools where the needs are greatest, and second, the LEA's quality management system has not been able to identify which different problems the schools are really grappling with based on both the students' academic performance and other qualities in the school's work. Part of the explanation may have to do with difficulties in dealing with certain short-term elements in national governance, such as different types of targeted government grants, but it may also have to do with the autonomy that each principal and school has in the Swedish school system. In the municipality studied, the LEA has not found a way so far, through its quality system, to prevent crises or declining results in schools. Despite the standardization of many structures and processes, there is still uncertainty among LEA managers about when clearer leadership is required or when data are insufficient to explain what problems the school faces (cf. Rorrer et al. 2008).

\section{Quality management system in the middle of the school system}

The LEA's quality management system seems broadly in line with the state's intentions and ambitions when it comes to achieving improved academic performance and increased equity between schools. The intermediate position between the state and the local schools that the LEA occupies in the Swedish school system in view of the quality management can be regarded, based on the results of this study, as somewhat friction free. However, at the same time, this is based on the fact that the LEA loyally follows the national intentions and the stipulations, that is, to design quality management and improvement work on the basis of local conditions and needs. Nevertheless, the relation between state and municipal responsibility (via the LEA) for schools' performance and quality development tends to dissolve due to various types of disruptions in governance. For example, the national targeted grants many times do not consider local conditions or national school improvement interventions such as CBS. This type of interconnection or meeting between the state and the municipality in terms of quality management seems to be interpreted somewhat differently by the LEA actors. Although LEA administrators can point to potential waste of state resources through specific earmarked state grants that the municipality feels compelled to apply for, they still rely more on government initiatives than the LEA managers do. The LEA managers highlight a clearer need for autonomy in relation to the state, but they still acknowledge the importance of certain state contributions to and interventions in the LEA's quality management system. One interpretation may be that the LEA managers' responsibility is partly eroded when the state finds itself in the LEA's sphere in a way that it was not before and to some degree takes over the task that belongs to the municipality under the Swedish Education Act. On 
an overall level, it is also possible to see what appears in this municipality's context as an attempt on the part of the state to integrate the similar tasks of the different levels of responsibility within the framework of a quality management system and convert them into common concerns. Thus, tight couplings have emerged between two of the overall subsystems (state and municipality via the LEA) in terms of quality management compared to what we have seen previously (cf. Rorrer et al. 2008; Orton and Weick 1990). At the same time, it is unclear whether this also interplay with loose couplings in the current local school system or whether the different levels have in fact begun to move in the same direction to possibly contribute to the results development sought for the schools (cf. Rorrer et al. 2008; Fullan 2009). Given the somewhat limited empirical evidence in this study, it is impossible, of course, to rule out that the indications of closer system connections on a comprehensive level are random and not dependent on conscious strategies or actions at either the state or the LEA level. What reinforces the uncertain picture is the statements by LEA officials that highlight the unpredictability of the state initiatives, especially the government grants that can be applied for, where both content and time extension can in principle be changed overnight. At the same time, it may be that the municipality in this case stands for the stability and coherence that may be needed for the effects of both national and local initiatives to be sustainable, which is something that previous research has also shown (cf. Campbell 2005; Hopkins and Woulfin 2015). The unpredictability of the national governance is, thus, offset by the stability of the (large) municipality's well-developed organization in terms of resources and competence. However, this interpretation needs further investigation, as prior research has often shown a lack of coherence as well as unintended variation in Swedish municipal quality management systems (cf. Jarl, Blossing, and Anderssson 2017).

\section{LEA strategies and continued research}

Through this study, understanding of the LEA's position in a school system has been deepened in terms of what fundamental strategies and actions are emphasized above others in a quality management system aimed at improving results and increasing equity. Although the LEA's quality management system includes several components that have been highlighted in previous research, such as the focus on and management of school improvement and joint commitment to improving school results (cf. Campbell and Murillo 2005), the performance trend measured in the compulsory school's final grades has not significantly improved so far. According to researchers, the balance between accountability for student outcomes and, for example, the construction of networks between schools or productive relations between superintendents and school leader teams needs to be maintained in order for the entire system to be affected (cf., for example, Fullan 2005; Lee et al. 2012; Louis 2013; Campbell and Murillo 2005; Henriksen 2018). In the municipality in question, there is a strong emphasis on data use to legitimize several strategies, which so far may have led to the forward-looking school improvement work and development work on teaching and learning having stuck at the school level without reaching the 
classrooms. Data usage at the school level is a contradictory phenomenon, as it is both time and competence demanding as well as potentially important for the planning of teaching (cf. Sun, Przybylski and Johnsson 2016), but this study has not focused on it. It is, therefore, important in future studies of LEA's quality management systems to investigate the significance and consequences of different strategies at the microlevel-for example, in what way the predetermined data that schools are expected to work with are really user friendly and possible to base decisions about teaching on (cf. Sun et al. 2016). At the same time, it is possible and important to investigate at the macro-level the hypothesis about the potential of the large municipality to stabilize the unpredictability of national governance through its quality management system and, conversely, whether it is the case that smaller municipalities are hit harder by this.

\section{Conclusion}

Based on this study's data and in relation to previous research, there is support for the LEA's potential to contribute to stability and coherence in relation to national governance and to local schools. Tentatively this is conditioned on the variability of couplings (both tight and loose) between the national and the municipal level. Furthermore, and possibly, this is valid in larger municipalities and there is a need for comparison data from middle- and small-sized municipalities, which this study has not included. There are indications of the possibility of strengthening the couplings between different subsystems and between the different LEA roles through the strategies used by the LEA in the quality management system, but the outcome in terms of increased equity is unclear. This finding may be due, among other things, to the difficulty of not only predicting the consequences of data use at the school level but also adapting leadership to each school's specific problems and needs.

Funding Open Access funding provided by Dalarna University.

Open Access This article is licensed under a Creative Commons Attribution 4.0 International License, which permits use, sharing, adaptation, distribution and reproduction in any medium or format, as long as you give appropriate credit to the original author(s) and the source, provide a link to the Creative Commons licence, and indicate if changes were made. The images or other third party material in this article are included in the article's Creative Commons licence, unless indicated otherwise in a credit line to the material. If material is not included in the article's Creative Commons licence and your intended use is not permitted by statutory regulation or exceeds the permitted use, you will need to obtain permission directly from the copyright holder. To view a copy of this licence, visit http://creativecommons.org/licen ses/by/4.0/.

\section{References}

Adolfsson, C-H., \& Alvunger, D. (2017). The nested systems of local school development: Understanding improved interaction and capacities in the different sub-systems of schools. Improving Schools, 20(3), 195-208. 
Adolfsson, C-H., \& Alvunger. D. (2020). Power dynamics and policy actions in the changing landscape of local school governance. Nordic Journal of Studies in Educational Policy, 6(2), 128-142. https:// doi.org/10.1080/20020317.2020.1745621.

Bryman, A. (2002). Samhällsvetenskapliga metoder [Social science methods]. Stockholm: Liber.

Campbell, C., \& Murillo, J. (2005). Big change question: Do local central authorities (LCAs) make a difference in school reform? Journal of Educational Change, 6, 77-89. https://doi.org/10.1007/ s10833-004-7785-1.

Cuban, L. (2013). Inside the black box of classroom practice: Change without reform in American education. Cambridge: Harvard Education Press.

Cohen, L, Manion, L. \& Morrison, K, (2011). Research methods in education. 7. ed. Milton Park, Abingdon, Oxon, [England]: Routledge

Datnow, A., Lockton, M. \& Weddle, H. (2019). Redefining or reinforcing accountability? An examination of meeting routines in schools. Journal of Educational Change. https://doi.org/10.1007/ s10833-019-09349-z

Fullan, M. (2005). Leadership and sustainability: System thinkers in action. Thousand Oaks: Corwin Press.

Felner, R. D., Favazza, A., Shim, M., Brand, S., Gu, K., \& Noonan, N. (2001). Whole school improvement and restructuring as prevention and promotion: Lessons from STEP and the project on high performance learning communities. Journal of School Psychology, 39(2), 177-202. https://doi.org/ 10.1016/S0022-4405(01)00057-7.

Felner, R. D., Bolton, N., Seitsinger, A. M., Brand, S., \& Burns, A. (2008). Creating a statewide educational data system for accountability and improvement: A comprehensive information and assessment system for making evidence-based change at school, district and policy levels. Psychology in the Schools, 45(3), 235-256. https://doi.org/10.1002/pits.20294.

Fullan, M. (2009). Large-scale reform comes of age. Journal of Educational Change, 10(2/3), 101-113. https://doi.org/10.1007/s10833-009-9108-z.

Håkansson, J. (2019). Leadership for learning in the preschool: preschool managers' perspectives on strategies and actions in the systematic quality work. Educational Management Administration \& Leadership, 47(2), 241-258. https://doi.org/10:1177/1741143217737294.

Håkansson, J., \& Sundberg, D. (2016). Utmärkt skolutveckling. Forskning om skolförbättring och måluppfyllelse [Excellent School Development. Research on School Improvement and Goal Achievement]. Stockholm: Natur \& Kultur.

Henriksen, Ø. (2018). Making Sense Across Levels in Local School Governance: Dialogue Meetings between a Superintendent and Subordinated School Leaders. Nordic Journal of International and Comparative Education, 2(2/3), 119-133. https://doi.org/10.7577/njcie.2752.

Henriksen, Ø., \& Aas, M. (2020). Enhancing system thinking-A superintendent and three principals reflecting with a critical friend. Educational Action Research. https://doi.org/10.1080/09650792. 2020.1724813.

Hopkins, M., \& Woulfin, S. L. (2015). School system (re)design: Developing educational infrastructures to support school leadership and teaching practice. Journal of Educational Change, 16(4), 371-377.

Jarl, M., Blossing, U., \& Andersson, C. (2017). Att organisera för skolframgång: strategier för en likvärdig skola [Organizing for school success: strategies for school equity]. Stockholm: Natur \& Kultur.

Kvale, S., \& Brinkman, S. (2014). Den kvalitativa forskningsintervjun [The qualitative research interview]. Lund: Studentlitteratur.

Leithwood, K., Sun, J., \& McCullough, C. (2019). How school districts influence student achievement. Journal of Educational Administration, 57(5), 519-539. https://doi.org/10.1108/JEA-09-2018-0175.

Lee, M., Louis, S. K., \& Anderson, S. (2012). Local education authorities and student learning: The effects of policy and practices. School Effectiveness and School Improvement: An International Journal of Research, Policy and Practice, 23(2), 133-158. https://doi.org/10.1080/09243453.2011. 652125.

Louis, S. K. (2013). Districts, local education authorities, and context of policy analysis. Journal of Educational Administration, 51(4), 550-555. https://doi.org/10.1108/09578231311325695.

Moos, L., Nihlfors, E., \& Paulsen, J. M. (2016). Directions for our investigation of the chain of governance and the agents. In L. Moos, E. Nihlfors \& J.M. Paulsen (Eds.), Nordic superintendents: Agents in a broken chain (pp. 1-24). Berlin: Springer. https://doi.org/10.1007/978-3-319-25106-6_1

Moos, L., Nihlfors, E., \& Paulsen, J. M. (Eds.). (2016). Nordic Superintendents: Agents in a Broken Chain. Berlin: Springer. https://doi.org/10.1007/978-3-319-25106-6_1. 
Nordholm, D. (2016). State policy directives and middle-tier translation in a Swedish example. Journal of Educational Administration, 54(4), 393-408. https://doi.org/10.1108/JEA-05-2015-0036.

Orton, J., \& Weick, K. E. (1990). Loosely coupled systems: A reconceptualization. The Academy of Management Review, 15(2), 203-223. https://doi.org/10.5465/amr.1990.4308154.

Patton, M. Q. (2015). Qualitative research \& evaluation methods: Integrating theory and practice (4th ed.). London: SAGE Publications Inc.

Paulsen, J. M., \& Henriksen, Ö. (2017). Mediation, collaborative learning and trust in Norwegian school governing: Synthesis from a Nordic research project. Nordic Journal of Comparative and International Education, 1(1), 68-84. https://doi.org/10.7577/njcie.1952.

Paulsen, J. M., \& Høyer, H. C. (2016). External control and professional trust in Norwegian school governing: Synthesis from a Nordic research project. Nordic Studies in Education, 36(2), 86-102. https://doi.org/10.18261/issn.1891-5949-2016-02-02.

Paulsen, J. M., Johansson, O., Nihlfors, E., Moos, L., \& Risku, M. (2014). Superintendent leadership under shifting governance regimes. International Journal of Educational Management, 28(7), $812-822$.

Prøitz, T. S., Mausethagen, S., \& Skedsmo, G. (2019). District administrators' governing styles in the enactment of data-use practices. International Journal of Leadership in Education. https://doi.org/ 10.1080/13603124.2018.1562097.

Rennstam, J., \& Westerfors, D. (2011). Att analysera kvalitativt material [Analyzing qualitative material]. In Ahrne, G. \& Svensson P. (Eds.), Handbok i kvalitativa metoder. Stockholm: Liber.

Rorrer, A. K., Skrla, L., \& Scheurich, J. J. (2008). Districts as institutional actors in educational reform. Educational Administration Quarterly, 44(3), 307-358.

Scott, W. (2008). Institutions and organizations: Ideas and interests. London: Sage.

Seller, W. (2005). Schools and school districts in educational reform: Examining the space in-between. Journal of Educational Change, 6, 1-5. https://doi.org/10.1007/s10833-004-7728-x.

Spillane, J. P., Parise, L. M., \& Sherer, J. Z. (2011). Organizational routines as coupling mechanisms: Policy, school administration, and the technical core. American Educational Research Journal, 48(2), 586-619. https://doi.org/10.3102/0002831210385102.

Sannerstedt, A. (2001). Implementering-hur politiska beslut genomförs i praktiken [Implementation: How political decisions are carried out in practice]. In Rothstein, B. (Ed.), Politik som organisation-Förvaltningspolitikens grundproblem. Stockholm: SNS förlag.

Sun, J., Przybylski, R., \& Johnson, B. J. (2016). A review of research on teachers' use of student data: From the perspective of school leadership. Educational Assessment, Evaluation and Accountability, 28(1), 5-33. https://doi.org/10.1007/s11092-016-9238-9.

Tashakkori, A., \& Teddlie, C. (2010). Sage handbook: Mixed methods in social and behavioral research. London: Sage.

Vetenskapsrådet (2017). God forskniningssed [Proper research conduct]. Stockholm: Vetenskapsrådet [Swedish Research Council].

Wahlström, N., \& Sundberg, D. (2017). Transnational curriculum standards and classroom practices: The new meaning of teaching. London: Routledge.

Wahlström, Ninni, \& Sundberg, Daniel (2017b). Kommuner som aktörer $i$ utbildningsreformer: implementeringen av läroplansreformen Lgr 11 (Rapport 2017:21) [Municipalities as actors in educational reforms: The implementation of the curriculum reform]. Uppsala: Institutet för arbetsmarknadspolitisk utvärdering (IFAU).

Weick, K. (1976). Educational organizations as loosely coupled systems. Administrative Science Quarterly, 21(1), 1-19.

Publisher's Note Springer Nature remains neutral with regard to jurisdictional claims in published maps and institutional affiliations. 